This is an author produced version of a paper published in Journal of Oral Rehabilitation. This paper has been peer-reviewed but does not include the final publisher proof-corrections or journal pagination.

Citation for the published paper:

Nilsson, Ing-Marie; Brogårdh-Roth, Susanne; Månsson, Johanna; Ekberg, EwaCarin. (2019). Temporomandibular pain in adolescents with a history of preterm birth. Journal of Oral Rehabilitation, vol. 46, issue 7, p. null

URL: https://doi.org/10.1111/joor.12782

Publisher: Wiley

This document has been downloaded from MUEP (https://muep.mah.se) / DIVA (https://mau.diva-portal.org). 
DR. ING-MARIE NILSSON (Orcid ID : 0000-0002-0550-8925)

Article type : Original Article

\section{Temporomandibular pain in adolescents with a history of}

\section{preterm birth}

\section{Running title: TMD pain in preterm born}

Nilsson Ing-Marie ${ }^{1}$, Brogårdh-Roth Susanne ${ }^{2,}$ Månsson Johanna ${ }^{3}$, EwaCarin Ekberg $^{4}$

${ }^{1}$ Center for Oral Rehabilitation, Norrköping, Sweden

${ }^{2}$ Department of Paediatric Dentistry, Faculty of Odontology, Malmö University, Malmö, Sweden

${ }^{3}$ Department of Psychology, Lund University, Lund, Sweden

${ }^{4}$ Department of Orofacial Pain and Jaw Function, Faculty of Odontology, Malmö University, Malmö, Sweden

Correspondence to:

Ing-Marie Nilsson, Center for Oral Rehabilitation, Folktandvården Druvan, SE 60182

Norrköping, Sweden

Phone +46101042919

Email: ing-marie.nilsson@ regionostergotland.se

This article has been accepted for publication and undergone full peer review but has not been through the copyediting, typesetting, pagination and proofreading process, which may lead to differences between this version and the Version of Record. Please cite this article as doi: 10.1111 joor. 12782

This article is protected by copyright. All rights reserved. 


\title{
ACKNOWLEDGEMENTS
}

The authors express their appreciation to all the participants of this study for taking the time to fill in the questionnaires. The Ethics Committee of the Medical Faculty of Lund University has approved previous studies from where the material was collected (Dnr LU 362-01, Dnr 618/2007) and also the present questionnaire study aimed at individuals 17-19 years of age (Dnr Etik H15 2013/39). The Faculty of Odontology, Malmö University, and the Public Dental Health in the Region of Östergötland (4-17-23) funded the study. The authors declare no conflict of interests.

\begin{abstract}
Aim: To evaluate the frequency of TMD pain among adolescents with a history of preterm birth compared to a matched control group.
\end{abstract}

Methods: A group of 192 preterm-born adolescents was followed up at the age of 17-19 years and compared to matched controls. Self-report questionnaires included screening questions about TMD pain, chronic diseases, general health, depression, anxiety, anger, antisocial behavior, and self-concept. TMD pain was defined as answering 'yes' to one or both of the following questions: "Do you have pain in the temple, face, temporomandibular joint, or jaws once a week or more?" and "Do you have pain when you open your mouth wide or chew once a week or more often?" Data analysis was performed using chi-square test and logistic regression model with likelihood ratio test.

Results: A TMD pain frequency of $23 \%$ of preterm-born adolescents and $26 \%$ among the controls was found, with no significant differences between the groups. Neither were there differences regarding anxiety, depression, anger, or self-confidence. Within the preterm group, adolescents with TMD pain registered tension and pain in the body, trouble sleeping,

This article is protected by copyright. All rights reserved. 
stomach pain, and feelings of hopelessness about the future. The controls with TMD pain, more reported having a bad life, feeling like a failure, and having bodily pain. Among tested background variables only TMJ locking or intermittent locking once a week or more was found to explain TMD pain in adolescents.

Conclusion: A high frequency of TMD pain was found in both groups, one possible explanation could be TMJ dysfunction.

Keywords: Adolescents, case-control study, preterm birth, psychosocial factors, screening questions, TMD pain

\section{Introduction}

Chronic pain can be regarded as a significant health issue affecting at least $20 \%$ of the adult population (1). Besides suffering from pain, impaired health and lower quality of life are consequences of chronic pain for both the patients and their closest family as for the society. Orofacial pain is the third most common cause of chronic pain with a prevalence of $10 \%$ to $15 \%$ in the adult population $(1,2)$. Orofacial pain is severely underdiagnosed and undertreated $(3,4)$. Of all chronic orofacial pains, Temporomandibular disorder (TMD) pain is the most common non-odontogenic condition (5). The prevalence of TMD pain in adolescence has been reported to be 2-6\% (6). The TMD pain prevalence among 17-19-yearold girls was $8-9 \%$ and $3-4 \%$ among boys (3).

As chronic pain is a complex disorder it is important to use the biopsychosocial model to understand the context of chronic illness (7). In a review by Burke et al an association between early-life stress or adversity and increased incidence of chronic pain in later life has been found (8). Furthermore, they discuss how painful physical events and procedures as well 
as stress in neonates play a key role in inducing alterations in pain processing. Their review has found that several psychological stressful events in early childhood predict chronic pain later in life. In a longitudinal study, Brattberg followed 335 children and found that the pain reports in childhood and early adolescence were associated with the report of pain in early adulthood (9). Young adults with a history of low birth weight (preterm and term) reported more chronic pain in the body compared to controls; moreover, an overall high percentage of those who reported moderate to very severe pain in the past four weeks at the age of 19 also did so 7-9 years later (10).

Furthermore, preterm birth has been shown to increase the risk for psychiatric disorders such as depression and anxiety during adolescence (11). Conversely, previous studies have shown that teenagers born prematurely are less likely to engage in risk-taking and antisocial behavior (12). In a Swedish study by Hallin and Stjernqvist (13), 52 children born before gestational week 29 were examined at 18-19 years of age with regard to cognitive, emotional, and behavioral functioning. In comparison with full-term-born controls, the preterm children had a significantly lower intelligence quotient, poorer educational achievements, and fewer followed a theoretical program in upper secondary school. In line with these results, Zwicker and Harris concluded from their systematic review that preterm birth has an impact on quality of life at various ages extending to adolescence and adulthood (14). The review evaluated certain factors associated with quality of life such as pain, emotional functioning (anxiety, mood, etc.), social functioning (behavior, communication, relations, etc.), and global health.

This article is protected by copyright. All rights reserved. 
The predictors for onset of facial pain and TMD pain in early adolescence have proven to be female gender, somatization, the number of other pain complaints, and life dissatisfaction (15). Adolescents with TMD pain described their pain to be recurrent and sometimes persistent. The physical problems paired with daily demands develop into a vicious circle which causes adolescents to oscillate between hope and despair (16). They develop pain management strategies in various ways, and seeking treatment to find an explanation for the cause of their pain is one such strategy (17).

As physical and psychological stressful events at early age is associated with chronic pain later in life it is of interest to evaluate TMD pain in relation to emotional and social impairment. The primary aim of this study was to evaluate the frequency of TMD pain among adolescents between 17-19 years who had been born premature in comparison to a matched control group of adolescents who had been born full-term. A second aim was to compare adolescents with and without TMD within each group, those born preterm and the controls. Given that premature children often go through many painful interventions at an early age, we expected a higher frequency of TMD pain in adolescents with a premature birth compared to adolescents who were born full-term (10). Furthermore, among the adolescents who were born premature, we hypothesized that a higher frequency of emotional and social impairments in comparison to full-term born adolescents.

\section{Material and methods}

\section{Study area}

This study was carried out in southern Sweden, and all preterm adolescents included in the study were born at the University hospitals of Malmö and Lund (18).

This article is protected by copyright. All rights reserved. 


\section{Study population}

All preterm adolescents invited to participate in this follow-up study originate from previous studies by Brogårdh-Roth (18). This cohort includes a study group and a control group identified retrospectively.

The present study was performed in 2013, when the participating preterm adolescents in the study group had reached 17-19 years. The original study sample included all adolescents born $\leq 32$ weeks of gestation born from 1994 to 1996 ( $n=192)$. Information about the child's gestational age, birth weight, and number of siblings was collected from the Swedish National Board of Health and Welfare after the Swedish Medical Birth Register granted access to the information.

In previous studies, a control group consisting of adolescents born full-term was matched with every preterm child entering the study population 2008 (19) by age, gender, immigrant background (defined as having at least one parent born outside the Nordic countries), dental clinic, and dentist. The same control adolescents were invited to participate in the present survey. If a case could not be located, the corresponding control was not eliminated from the sample.

The original 192 preterm (PT) adolescents and 192 matched adolescents (C) were invited to participate in this study (Figure 1). A total of 145 preterm adolescents and 140 controls agreed to participate in the present study.

This article is protected by copyright. All rights reserved. 
In this study, the term 'preterm' (PT) is used to describe children born at 32 weeks of gestation or earlier, 'very preterm' (VPT) to describe children born from 29-32 weeks of gestation, and 'extremely preterm' (EPT) to describe children born from 23-28 weeks of gestation.

\section{Questionnaire}

A questionnaire was sent by mail to all participants. The questionnaire was of self-report design and included demographics (age, gender, being a twin, current education, and socioeconomics). Having TMD pain was defined as answering 'yes' to one or both of the following questions: "Do you have pain in the temple, face, temporomandibular joint, or jaws once a week or more?" and "Do you have pain when you open your mouth wide or chew once a week or more often?" These screening questions about TMD pain have both high reliability and validity in adolescents (20). Questions were asked regarding medical health and included general health problems, disability, and daily medication.

The following descriptions were used for chronic disease:

1) A disorder which is disabling and obviously chronic or incurable, or

2) A disorder of at least three months during a one-year period and interfering with daily life functioning and/or needing treatment or special aids during at least three months.

The definition for 'general health problems' involved an individual having medical problems but of lesser severity or duration, for example, allergies or minor respiratory disorders. A list of other questions used in this study can be found in Table 1 (21). However, the questionnaire also contained other items with focus on dental fear, experience of dental care and oral health behaviour (22).

This article is protected by copyright. All rights reserved. 
The questionnaire included also the Swedish version of Beck Youth Inventories (BYI) (23) includes five self-report inventories for individuals between 7-18 years. In a study from 2009, the BYI showed good internal consistency and test-retest stability (24). Questions included in the depression inventory are in line with the depression criteria of the Diagnostic and Statistical Manual of Mental Health Disorders, Fourth Edition (DSM-IV) and included items related to negative thoughts about the self and the future, feelings of sadness and guilt, and problems with sleep. The anxiety inventory investigates worries about school, negative reactions of others, fears, and physiological symptoms related to anxiety. The anger inventory measures thoughts about being treated unfairly and feelings of anger. The disruptive behavior inventory identifies delinquent and/or oppositional-defiant behavior. The self-concept inventory investigates cognitions of competence and feelings of self-worth. The total raw scores for each inventory range from 0-60. Higher scores on the inventories for depression, anxiety, anger, and disruptive behavior indicate more symptoms. A higher score on the selfconcept inventory indicates more positive self-concept. Swedish gender-specific norms for children and adolescents 9-18 years of age were used (23).

Seven variables of possible importance for TMD pain in adolescents were selected. Three of these variables were single questions from BYI (Table 1). The four other variables are distributed in Table 2. The rationale for the selection of factors was based on factors associated with quality of life in preterm born adolescents, identified risk factors for facial pain and TMD pain in early adolescence, and how adolescents describe they are affected in daily life $(14,15,25)$. TMD pain was the dependent variable.

This article is protected by copyright. All rights reserved. 
Written information about the study was sent by post to the parents and adolescents, including information about confidential and voluntary participation with the right to discontinue participation at any time. A written informed consent form was attached along with the questionnaires to request the parents' and the adolescents' consent.

\section{Statistical analyses}

The chi-square test was used to compare the distribution of variables in preterm and control groups, between the very preterm and extremely preterm groups, as well as between individuals with or without TMD pain. Data were analysed using logistic regression model with likelihood ratio test. The Statistical Package for the Social Sciences (SPSS), version 16.0 and 21.0 and 23.0 was used.

\section{Results}

The questionnaire was sent to 192 preterm adolescents and 192 controls (Figure 1). Seventysix percent of the preterm adolescents (67 boys and 78 girls), and $73 \%$ of the control group individuals ( 69 boys and 71 girls) agreed to participate and returned the questionnaire (these participants were not matched). At the time of the questionnaire, the mean age for the preterm group was 18.3 years (range 16.8-19.8 years) and 18.4 years (range 16.8-19.9 years) for the control group. An analysis of those who dropped out of the study shows a mean age for the preterm group of 18.1 years (range 16.4-19.8), and 18.1 years for the control group (range 16.4-19.8). Moreover, significantly more boys than girls among the preterm-born adolescents declined participation. Among the controls, there were no differences concerning gender.

This article is protected by copyright. All rights reserved. 
Significant differences between the preterm and control groups were found including a higher frequency for twins $(<0.01)$, chronic diseases $(<0.01)$ and taking daily medication $(<0.05)$ in the preterm group compared with the control group. Twenty-six adolescents with TMJ locking or intermittent locking had TMD pain significantly more often in both groups.

A high frequency of TMD pain was found in adolescents between 17-19 years without any difference between preterm and full-term-born adolescents. Thirty-three (23\%) preterm-born adolescents and 36 (26\%) of the adolescents in the control group answered 'yes' to one or both of the screening questions for TMD pain. Thirty-two adolescents were extremely preterm born, and 113 were very preterm born, without any difference $(\mathrm{P}=0.412)$ between these groups in relation to TMD pain.

Significantly more individuals with TMD pain were found among both cases and controls with locking and intermittent locking (Table 2). No gender difference in TMD pain was found in the control group (Table 2).

In addition, no differences were found between preterm group and the control group regarding anxiety, depression, anger, or self-concept according to BYI (23). However, disruptive behavior was found significantly $(\mathrm{P}=0.02)$ more often in the control group compared to the preterm group. After analyzing single items extracted from BYI, significantly more individuals among the controls registered feeling hopeless about the future compared to the preterm group (Figure 2). In the preterm group, a significant number of adolescents with TMD pain reported tension in the body $(\mathrm{P}<0.05)$, trouble sleeping $(\mathrm{P}<0.01)$, pain in the stomach $(\mathrm{P}<0.01)$, hopelessness about the future $(\mathrm{P}<0.001)$, and pain in the body $(\mathrm{P}<0.01)$. Among adolescents with TMD pain in the control group, significantly more

This article is protected by copyright. All rights reserved. 
reported that they had a bad life $(\mathrm{P}<0.05)$, felt like a failure $(\mathrm{P}<0.01)$, and had pain in the body $(\mathrm{P}<0.05)$.

Adolescents with TMD pain, both preterm and controls, had increased symptoms of depression and disruptive behavior compared to those without TMD pain. (Table 3). Furthermore, a significantly increased level of anxiety was found in full-term-born adolescents without TMD pain compared to those with TMD pain (Table 3).

Among seven possible factors of importance for TMD pain only the variable locking or intermittent locking once a week or more was found to be an explanatory factor for adolescents with TMD pain $(\mathrm{P}<0.000$, OR 6.632).

\section{Discussion}

The frequency of TMD pain in the group of preterm-born adolescents was found to be high, as was the frequency in the control group consisting of full term-born adolescents. No significant differences between the groups were found; therefore, the first hypothesis must be rejected. A high frequency of TMD pain in the preterm group was expected, as this group has been through early painful interventions that we know may result in pain later in life (10). Literature describes increasing evidence of an association between early-life stress and the increased incidence of chronic pain later in life (8). What is unexpected in this study is the high frequency of self-reported TMD pain in the control group and for reasons that are not obvious. Furthermore, no significant differences were found between gender, in contrast to most studies showing a higher prevalence of TMD pain among girls $(3,6,26)$. The most likely explanation was that the controls were not representative of the general population regarding TMD pain. Our control group might have some characteristics with importance for 
TMD pain that we have not detected. Among the preterm adolescents, TMD pain was more common among the girls, as hypothesized.

Is there a reason to believe that pain/TMD pain has increased among adolescents over the years? For the sake of comparison, Franco-Micheloni found a prevalence of 25.2\% TMD pain among 12- to 14-year-old adolescents in a Brazilian study from 2015 (27). In contrast, a recent population-based study in Sweden among 24,408 individuals aged 10-19 found selfreported TMD jaw pain between $17-18$ years to be approximately 5\% in girls and $1.5 \%$ in boys. In addition, TMD pain upon jaw movement was reported by approximately $2.5 \%$ of girls and $1 \%$ of boys (26).

It is important to consider that "frequency" is not comparable to "prevalence" and that the frequency can be high in a specific sample, such as in our study. In spite of that the adolescents were not told about the TMD pain previously to the investigation a remarkable high frequency was found. However, both in cases and controls, having TMD pain was associated with emotional and social impairments according to BYI. Unfortunately, it is not possible to further interpret these results as the screening questions were the only questions specifically related to TMD. The screening questions about TMD pain are found to have good reliability and validity among adolescents, which means that almost all of those who answered 'yes' to one or both of the questions have a TMD pain diagnosis (20). These questions are now used on a regular basis in Public Dental Service in Sweden. Screening for TMD pain is one way to identify adolescents in need of help (28). These screening questions could also be useful in the public health service to find and refer adolescents with TMD pain to a dentist and be offered treatment (17). This makes it possible to longitudinally follow the development of TMD pain in children and adolescents both on a population basis and in specific groups like the preterm born adolescents in our study.

This article is protected by copyright. All rights reserved. 
Our intention was to use instruments that are validated among adolescents and represent the same domains as Axis II-instruments used in Research Diagnostic Criteria for Temporomandibular Disorders, RDC/TMD, which was the most commonly used diagnostic system at the time of the study. Therefore the Swedish version of Beck Youth Inventories was used.

The finding that both groups of adolescents with TMJ locking/intermittent locking often have TMD pain is in accordance with our clinical experience. This is reported when adolescents describe their TMD pain problems and how they are affected in daily life (25). This was the only variable found among six other factors to be of possible importance for TMD pain in adolescents. This is an important finding making us understand the impact of this dysfunction on TMD pain. Therefore, clinicians have to identify TMJ locking/intermittent locking at an early stage. When screening for TMD pain using the two screening questions (used in this study) a third question is nowadays added to identify TMJ dysfunction "Does your jaw lock or become stuck once a week or more?". These three questions (3Q/TMD) have been validated from the age of 18 years and above. 3Q/TMD was found to be an applicable, costeffective and valid tool to recognize patients in need of further TMD examination and management (29).

Adolescents in the preterm group with TMD pain also registered high for tension in the body, sleeping difficulties, pain in the stomach, feelings of hopelessness about the future, and pain in the body. This is similar to other studies where adolescents with self-reported TMD pain also report pain in various other parts of the body as well as feelings of hopelessness $(15,16$, 28).

This article is protected by copyright. All rights reserved. 
A study investigating the health behavior of school-aged children during 2013-14 showed that self-reported somatic and mental problems have increased, especially among 13- and 15year-old girls (30). Globally, the most common mental disorders are depressive disorders and anxiety disorders. These disorders sharply increase during the time between childhood and adolescence (31). In this study, adolescents with TMD pain in both groups had increased levels of depressive symptoms, which is in accordance with earlier findings among adolescents with TMD pain where they reported elevated depressions scores (28).

Similar to other studies, the preterm-born individuals reported fewer problems with delinquency and risk-taking behavior. Otherwise, no difference was found between the groups with regard to socio-emotional problems. Neither did they differ in their estimations of quality of life or future expectations. In contrast, the full-term individuals with TMD pain reported having a bad life, feeling like a failure, and having pain in the body. They seem to feel worse than the preterm individuals, even though they all have TMD pain. This could be explained by the knowledge that preterm individuals in general are well taken care of by their families, making them well-supported in their life. Dissatisfaction with life has been found to be one of the predictors for developing TMD in adolescence (15). Stress is a factor in school and in society in general, and this widely affects adolescents. A group of adolescents with TMD pain described demands and stress mainly related to school caused them to feel tense, and this tension gives them pain (16). In the present study, we did not ask questions specifically about stress, but it may be one of the reasons contributing to the high frequency of TMD pain.

This article is protected by copyright. All rights reserved. 


\section{Concluding thoughts and suggestions for future research}

It is worth noting that a frequency of more than $20 \%$ regarding TMD pain was found in preterm as well as in full-term-born individuals between the ages of 17-19 years. Identifying these individuals and offering them treatment is of great importance, and this can be done by TMD pain screening in general dentistry. There is a need for prospective longitudinal studies with focus on predictors, and using DC/TMD Axis I and Axis II, of these two groups regarding TMD pain in the ages 20-30 years, as pain in general among adolescents is associated to pain in adult life(9).

\section{References}

1. Breivik H, Collett B, Ventafridda V, Cohen R, Gallacher D. Survey of chronic pain in Europe: prevalence, impact on daily life, and treatment. Eur J Pain. 2006;10:287-333.

2. Von Korff M, Dworkin SF, Le Resche L, Kruger A. An epidemiologic comparison of pain complaints. Pain. 1988;32:173-183.

3. Nilsson IM, List T, Drangsholt M. Prevalence of temporomandibular pain and subsequent dental treatment in Swedish adolescents. J Orofac Pain. 2005;19:144-150.

4. Lovgren A, Marklund S, Visscher CM, Lobbezoo F, Haggman-Henrikson B, Wanman A. Outcome of three screening questions for temporomandibular disorders (3Q/TMD) on clinical decision-making. J Oral Rehabil. 2017;44:573-579.

5. McNeill C. Management of temporomandibular disorders: concepts and controversies. J Prosthet Dent. 1997;77:510-522.

6. Drangsholt M, LeResche L. Temporomandibular Disorder Pain. In: Crombie C, Linton, LeResche, ed. Epidemiology of Pain. Seattle: IASP Press; 1999: 203-233.

7. Meints SM, Edwards RR. Evaluating psychosocial contributions to chronic pain outcomes. Progress in neuro-psychopharmacology \& biological psychiatry. 2018.

8. Burke NN, Finn DP, McGuire BE, Roche M. Psychological stress in early life as a predisposing factor for the development of chronic pain: Clinical and preclinical evidence and neurobiological mechanisms. Journal of neuroscience research. 2016.

9. Brattberg G. Do pain problems in young school children persist into early adulthood? A 13-year follow-up. Eur J Pain. 2004;8:187-199.

10. Iversen JM, Indredavik MS, Evensen KA, Romundstad PR, Rygg M. Self-reported Chronic Pain in Young Adults With a Low Birth Weight. Clin J Pain. 2016.

11. Lindstrom K, Lindblad F, Hjern A. Psychiatric morbidity in adolescents and young adults born preterm: a Swedish national cohort study. Pediatrics. 2009;123:e47-53.

12. Allin M, Rooney M, Cuddy M, Wyatt J, Walshe M, Rifkin L et al. Personality in young adults who are born preterm. Pediatrics. 2006;117:309-316.

13. Hallin AL, Hellstrom-Westas L, Stjernqvist K. Follow-up of adolescents born extremely preterm: cognitive function and health at 18 years of age. Acta Paediatr. 2010;99:1401-1406. 14. Zwicker JG, Missiuna C, Harris SR, Boyd LA. Developmental coordination disorder: a review and update. European journal of paediatric neurology : EJPN : official journal of the European Paediatric Neurology Society. 2012;16:573-581.

This article is protected by copyright. All rights reserved. 
15. LeResche L, Mancl LA, Drangsholt MT, Huang G, Von Korff M. Predictors of onset of facial pain and temporomandibular disorders in early adolescence. Pain. 2007;129:269-278. 16. Nilsson IM, List T, Willman A. Adolescents with temporomandibular disorder pain-the living with TMD pain phenomenon. J Orofac Pain. 2011;25:107-116.

17. Nilsson IM, Willman A. Treatment Seeking and Self-Constructed Explanations of Pain and Pain Management Strategies Among Adolescents with Temporomandibular Disorder Pain. Journal of oral \& facial pain and headache. 2016;30:127-133.

18. Brogardh-Roth S. The preterm child in dentistry. Behavioural aspects and oral health. Swed Dent J Suppl. 2010:11-85.

19. Brogardh-Roth S, Stjernqvist K, Matsson L. Dental behavioural management problems and dental caries prevalence in 3- to 6-year-old Swedish children born preterm. Int J Paediatr Dent. 2008;18:341-347.

20. Nilsson IM, List T, Drangsholt M. The reliability and validity of self-reported temporomandibular disorder pain in adolescents. J Orofac Pain. 2006;20:138-144. 21. Westbom L, Kornfalt R. Chronic illness among children in a total population. An epidemiological study in a Swedish primary health care district. Scand J Soc Med. 1987; 15:87-97.

22. Brogardh-Roth S, Mansson J, Ridell K, Alward L, Hellen-Halme K, Ekberg E. Five years' follow-up of dental fear and anxiety, experience of dental care and oral health behaviour in Swedish preterm and full-term adolescents. BMC oral health. 2017; 17:145.

23. Beck JS BA, Jolly JB, Tideman E, Näswall K. Beck ungdomsskalor: manual. Svensk version (bedömning av emotionell och social problematik hos barn och ungdomar). 1 ed. Stockholm Harcourt Assessment; 2007.

24. Thastum M, Ravn K, Sommer S, Trillingsgaard A. Reliability, validity and normative data for the Danish Beck Youth Inventories. Scand J Psychol. 2009;50:47-54.

25. Nilsson I-M, List T, Drangsholt M. Headache and Co-morbid Pains Associated with TMD Pain in Adolescents. J Dent Res. 2013;92:802-807.

26. Lovgren A, Haggman-Henrikson B, Visscher CM, Lobbezoo F, Marklund S, Wanman A. Temporomandibular pain and jaw dysfunction at different ages covering the lifespan--A population based study. Eur J Pain. 2016;20:532-540.

27. Franco-Micheloni AL, Fernandes G, de Godoi Goncalves DA, Camparis CM.

Temporomandibular Disorders in a Young Adolescent Brazilian Population: Epidemiologic Characterization and Associated Factors. Journal of oral \& facial pain and headache. 2015;29:242-249.

28. Nilsson IM, Drangsholt M, List T. Impact of temporomandibular disorder pain in adolescents: differences by age and gender. J Orofac Pain. 2009;23:115-122.

29. Lovgren A, Visscher CM, Haggman-Henrikson B, Lobbezoo F, Marklund S, Wanman A. Validity of three screening questions (3Q/TMD) in relation to the DC/TMD. J Oral Rehabil. 2016;43:729-736.

30. Health Behaviour in School-aged Children (HBSC). Sweden: WHO study; 2013/14. 31. Whiteford HA, Degenhardt L, Rehm J, Baxter AJ, Ferrari AJ, Erskine HE et al. Global burden of disease attributable to mental and substance use disorders: findings from the Global Burden of Disease Study 2010. Lancet. 2013;382:1575-1586.

This article is protected by copyright. All rights reserved. 
Table 1. Description of questions and possible answers included in the questionnaire sent to both a group of adolescents who were born preterm and a group who were born full-term.

\begin{tabular}{ll}
\hline Questions & Answers \\
\hline $\begin{array}{l}\text { Chronic disease } \\
\text { Daily medication }\end{array}$ & $0=$ no, 1= yes \\
TMJ locking or intermittent & \\
locking once a week or more & \\
often &
\end{tabular}

BYI:

Anxiety (max score)

moderate $<74$, slightly increased $75-89$, increased $>90$

Depression (max score)

Anger (max score)

Disruptive behavior (max score)

Self-concept

very low $<10$, low $11-25$, moderate $26-89$, high $>90$

Single question from BYI

$0=$ always, $1=$ often, $2=$ sometimes, $3=$ never

Dichotomized: $0=$ always and often, $1=$ sometimes and never

I worry about how I will cope

with schoolwork

I am worried about what will

happen to me in the future

I think I have a bad life

I feel like a failure

I feel hopeless when I think of the

future $\neq$

I feel tension in my body

I have pain in my body $\neq$

I have a stomach ache

I have trouble sleeping ₹

I sleep poorly

Scores have been transformed to percentiles and symptom severity is classified according to the following cut-offs: $\geq 90^{\text {th }}$ percentile highly elevated; $75^{\text {th }}$ to $89^{\text {th }}$ percentile slightly elevated; $\leq 74^{\text {th }}$ percentile average. In the self-concept inventory, the following cut-offs are used: $\geq 90^{\text {th }}$ percentile high self-concept; $26^{\text {th }}$ to $89^{\text {th }}$ percentile average self-concept; $11^{\text {th }}$ to $25^{\text {th }}$ percentile somewhat low self-concept; $\leq 10$ percentile very low self-concept (23). $\neq=$ Variables used in the logistic regression analysis.

This article is protected by copyright. All rights reserved. 
Table 2. Demographics of general health among adolescents who were born preterm compared with a control group in regard to TMD pain.

\begin{tabular}{|c|c|c|c|c|c|c|}
\hline \multirow{5}{*}{$\begin{array}{l}\text { TMD pain } \\
\text { TMD }\end{array}$} & & \multicolumn{3}{|c|}{ Group } & \\
\hline & Preter & & & Control & & \\
\hline & $n=145$ & & & $n=140$ & & \\
\hline & Yes & No & & Yes & No & \\
\hline & $\mathrm{n}=33$ & $\mathrm{n}=112$ & P-value & $\mathrm{n}=36$ & $\mathrm{n}=104$ & P-value \\
\hline Gender $\neq$ & & & 0.004 & & & 0.148 \\
\hline Boy & 8 & 59 & & 14 & 55 & \\
\hline Girl & 25 & 53 & & 22 & 49 & \\
\hline $\begin{array}{l}\text { Nordic } \\
\text { background }\end{array}$ & 26 & 94 & 0.492 & 30 & 85 & 0.829 \\
\hline Twin & 8 & 39 & 0.254 & 0 & 1 & 0.555 \\
\hline Chronic disease $\neq$ & 7 & 24 & 0.979 & 3 & 10 & 0.819 \\
\hline Allergy or asthma & 15 & 30 & 0.042 & 12 & 21 & 0.109 \\
\hline $\begin{array}{l}\text { Taking daily } \\
\text { medication }\end{array}$ & 12 & 21 & 0.034 & 6 & 11 & 0.139 \\
\hline $\begin{array}{l}\text { TMJ locking or } \\
\text { intermittent } \\
\text { locking } \neq \\
\text { (once a week or } \\
\text { more often) }\end{array}$ & 16 & 9 & 0.000 & 10 & 7 & 0.001 \\
\hline
\end{tabular}

$\neq=$ Variables used in the logistic regression analysis.

This article is protected by copyright. All rights reserved. 
Table 3. According to Beck Youth Inventories for adolescents(23), levels of anxiety, depression, anger, disruptive behavior, and self-concept, in adolescents with or without TMD pain in a group of adolescents with a history of preterm birth compared with a control group. Percentiles for scores to be average $\leq 74$, slightly increased $75-89$ and very increased to be $\geq$ 90. The scores for self-concept are interpreted to be very decreased $\leq 10^{\text {th }}$ percentile, slightly decreased 11-25, average 26-89, and high self-concept is $\geq 90^{\text {th }}$ percentile. The P-value is the analysis within preterm and control groups respectively.

\begin{tabular}{lcccccc}
\hline & Preterm & Preterm & P- & Control & Control & P- \\
TMD pain & Yes & No & value & Yes & No & value \\
& $n=33$ & $n=112$ & & $n=36$ & $n=104$ &
\end{tabular}

\begin{tabular}{|c|c|c|c|c|c|}
\hline Anxiety & \multicolumn{4}{|c|}{0.282} & $\mathbf{0 . 0 3 0}$ \\
\hline Average & 15 & 64 & 18 & 69 & \\
\hline Slightly increased & 13 & 28 & 6 & 17 & \\
\hline Very increased & 3 & 7 & 7 & 6 & \\
\hline
\end{tabular}

Depression

Average

Slightly increased

Very increased

Anger

Average

Slightly increased

Very increased
$18 \quad 85$

99

$\begin{array}{ll}5 & 8\end{array}$

0.001

20

4

6

0.167

$24 \quad 91$

$6 \quad 5$

27
0.021

79

8

7

\section{Disruptive behavior}

Average

Slightly increased

$\begin{array}{cc}25 & 91 \\ 3 & 10 \\ 4 & 2\end{array}$

0.023

$\begin{array}{cc}23 & 80 \\ 5 & 8 \\ 4 & 6\end{array}$

0.053

Very increased

Self-concept

Very decreased

Slightly decreased

Average

High

$\begin{array}{cc}1 & 1 \\ 7 & 10 \\ 22 & 75 \\ 2 & 17\end{array}$

0.404

$\begin{array}{cc}24 & 80 \\ 4 & 7 \\ 4 & 7\end{array}$

0.045

0.298

Chi-Square

This article is protected by copyright. All rights reserved. 


\section{Figure legends}

Figure 1. Flowchart of adolescents included in the study. At the start of the study, 192 adolescents from the control group were matched by age and gender to the adolescents in the preterm group. Adolescents between 17-19 years from both groups participated in the study. In this study, the term 'preterm' (PT) is used to describe children born at 32 weeks of gestation or earlier. Among PT, 'very preterm' (VPT) describe children born between 29-32 weeks of gestation, and 'extremely preterm' (EPT) describe children born between 23-28 weeks of gestation (WHO).

Figure 2. Single items extracted from BYI (23) distributed in preterm-born children and controls born full-term. Each item describes number of patients who answered 'always' or 'often' to the questions.

This article is protected by copyright. All rights reserved. 
Figure 1

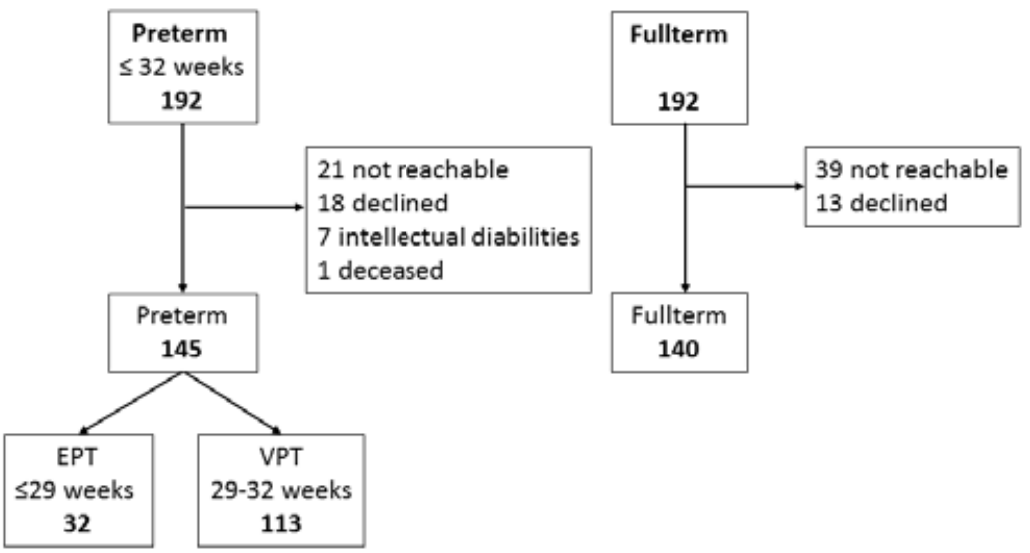

Figure 2

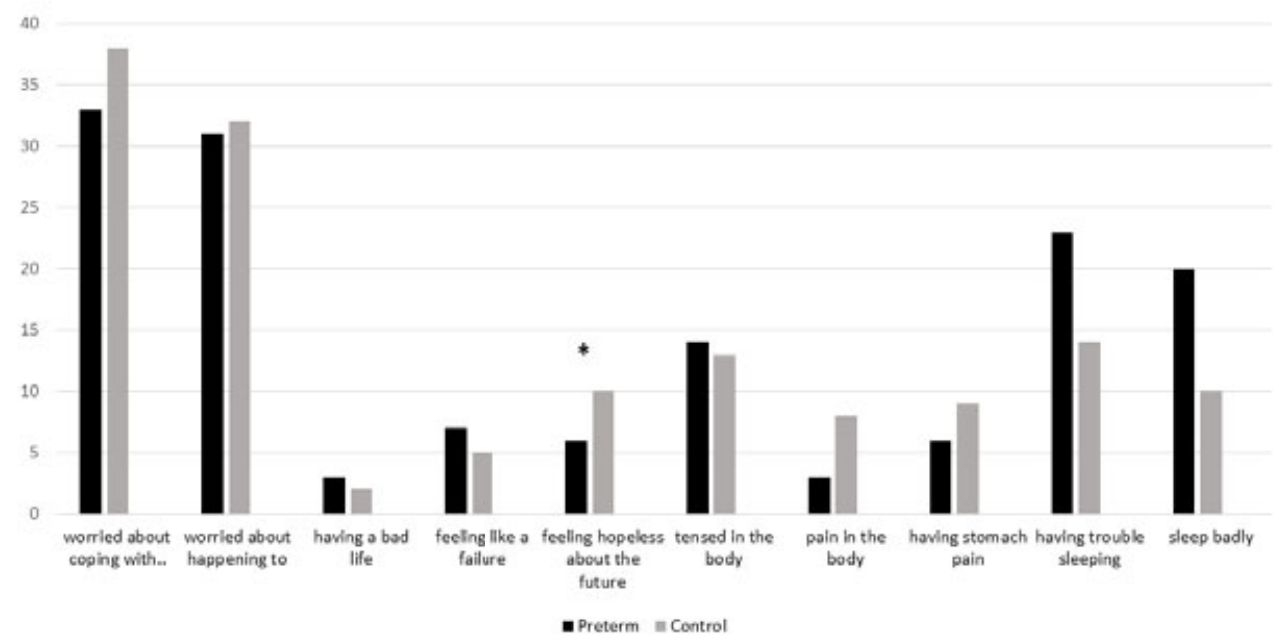

Chi-square test, ${ }^{*} P=<0.05,{ }^{* *} P=<0.01,{ }^{* * *} P=<0.001$ 